\title{
Deeds not words: Performance and management analysis of community water supply system at Pasthali, Kavre, Nepal
}

\author{
Dongol, R. ${ }^{1^{*}}$, Khadka, M. ${ }^{1}$, and Kharel, R.P. ${ }^{2}$ \\ ${ }^{1}$ Nepal Engineering College, Center for Postgraduate Studies, Lalitpur \\ ${ }^{2}$ Melamchi Water Supply Development Board, Kathmandu
}

\begin{abstract}
The study was carried out to assess the performance and management analysis of Pasthali Water Supply System. Various data collection tools such as questionnaire survey, field observation and key informant interviews were used along with water quality analysis at the source, treatment plants, point of delivery and use. The filter bed media analysis was also carried out to assess the uniformity in the bed media. Mcrobial contamination in treated water was found due to improper sand granular used in filtration unit that hinder efficient removal of the microbes, lack of chlorination in the unit caused increase in microbial contamination at the point of delivery along with the unhygienic environment at the distribution tanks. Manual chlorine addition for three days was found to be effective in reducing microbial contamination drastically, but the water is recontaminated once delivered and stored at the household level. Improper handling and unhygienic storage location were found to be the major causes of increased contamination at households. The status of the water source is not safe either and seeks intermediate attention. The operation and management of Pasthali Water Supply System solely depends on water tariff and bears financial loss annually. The study also concludes that there is surplus of treated water termed as non-revenue water in the system. Proper granulation of the sand in the filtration unit and chlorination are must to ensure the safe water along with the awareness on the water management at the household levels. Supplying of non-revenue water to the nearby villages could be a potential to generate resources that ultimately strengthen financial aspects of the system and build resilience to financially break-down in the future.
\end{abstract}

Key words: Microbial contamination, Non-revenue water, Pasthali Water Supply System, Performance.

\begin{abstract}
Introduction
The biggest challenge faced by the Government of Nepal (GoN) is to provide safe water and improved sanitation facilities to its all people. For underdeveloped countries like Nepal, the degree of ease of access to safe water is the indicator of the health status of the people. The number of water taps per 1000 persons is a better indication of health than the number of hospital beds (Nepal, 2016). Therefore, it is essential to provide a regular service facility of safe drinking water to the people because water is the basic need of human being. The regular service facility of drinking water involves active function of user committee, access of the good quality water and its sustainability.
\end{abstract}

With the dawn of $8^{\text {th }}$ five-year development plan (1992-1997), the gateway to water supply and sanitation sector was opened in the international and national arena thereby inviting many more donor agencies to assist the government in this sector. This resulted in a significant leap on the national coverage of water supply and

*Corresponding author, email address: robert@nec.edu.np sanitation along with a shif t emerged - in the community contribution from mere voluntar y kind contribution to the community management. The Government's National Water Supply Sector Policy - 1998 also substantiated this process, which focused on the participatory approach to service delivery. The government made a major policy shif $t$ and this new approach has assigned facilitative role for the government and has emphasized that the role of beneficiaries, local authorities and Non Gover nmental Organizations (NGOs) in scheme implementation. Government of Nepal (GoN), with the assistance of a number of multilateral and bilateral donors, has made considerable effort to provide improved water supply to the people living in the both urban and rural areas of Nepal. In the twelve periodic plans achievement status of sustainable access to source of drinking water area is 85\% (GoN \& UN, 2013). Government of Nepal aims to supply safe and easilty accessible water to all its citizens by 2017 (HMG -N, 2005). 
The focal issue in the water supply and sanitation sector today is how can schemes be sustained longer. Once the service delivery points are in place, and the initial capital investment is made, the ideal expectation is that the consumers own them and carry out post-construction supervision and maintenance activities to derive the desired benefits for a minimum duration of the design period. Reality however, differs. Several drinking water supply projects in general and gravity flow systems in particular are not functioning properly. Only $18 \%$ schemes are r unning smoothly catering the services as expected, 38.9\% schemes need minor repair, $11.8 \%$ schemes require major repairs, $21 \%$ scheme needs rahabitation and $9.1 \%$ need complete reconstruction and $1.6 \%$ schemes are non-refunctionable (NMIP/DWSS, 2011). It has been found that the most rural water supply schemes completed over the past decades have not been able to meet their design periods and standards. Lack of any further regular follow up and continuous monitoring mechanisms in many water supply systems after the completion of the project coupled with number of reasons lik e inadequate maintenance, design or construction defects, natural disaster and water rights disputes, lack of standard operating procedure, the system gets degraded continuously.

The treatment units in Pasthali Water Supply System are constructed to bring down different impurities present in water to acceptable limits to secure good health among the beneficiaries. The study was carried out to assess the per formance and management of the system.

\section{Materials and Methods Pasthali water supply system}

Pasthali water supply project lies in W ard No. 13 of Panauti Municipality, Kavreplanchok District. Kavre is one of the hill districts in Bagmati Zone of Central Development Region in Nepal. The system came in existence in 1998 and it was upgraded with sedimentation tank and filtration units in 2012/13 by Department of water supply and sewerage (DWS S, 2012). The project was implemented by Water Supply and Sanitation Division Office, Kavre. The communities were also involved in each steps of the project cycle. The implementation was done in the close coordination with local water users committee. The local water users also rendered substantial community contributions: kind and cash. Nearly about $10 \%$ of the total cost of the project was contributed by the community. All the lands required for the construction of various str uctures were provided by the local community. Pasthali Water Supply system serves a total of 3,051 populations residing in 509 households scattered in the major seven settlements namely; Salmitar, Makaitar, Butapole, Mahat gaun and Soudole, School area and Khatrigau. Altogether, 215 water taps, including 45 public and 170 private, were installed. The private tap owner pays monthly water tariff. The members of the community tap pay the tariff collectively (DWSS, 2012). The supply is intermittent, one hour in the morning and one hour in the evening. Pasthali Water Supply System gets water from two sources; a river source named Bete Khola (a river) and Tileshwor (a spring source). At present, there is one unit of sedimentation tank, filtration and chlorination unit to improve the water quality of the system (Fig. 1). The filtration unit has three chambers: two working at a time and third one is the stand by unit. The treated water is then distributed to the households through five distribution tanks strategically placed at the various locations and treated water flows under gravity. The tapped discharge of the system is 3 lps. But due to various problems, the water entering the treatment site is always less than aforementioned amount.

\section{Datat collection method}

Primary data was collected using various tools such as field visit and observation, Key Informant Interview (KII), Questionnaire Survey, Water analysis and filter media sieve analysis. Water samples from the source, treatment system (as represented by $S 1$.. Sn in Fig. 1), water samples from seven tap stands and 14 household water samples were collected and analyzed. F or water-quality monitoring in small communities, a small size of sample for microbiological quality and turbidity, free residual chlorine and $\mathrm{pH}$ was considered. There is no concer n of how many other physical or chemical variables are to be measured (WHO, 1999). The Fig. 2 represents methodological framework adopted in the study. The water quality at the source was analyzed once, for the basic water quality parameters such as $\mathrm{pH}$, turbidity, electrical conductivity, iron, manganese at the laboratory of Environment and Public Heath Organization (ENPHO). Secondly, the on-site water quality assessment for two critical parameters such as turbidity and total/fecal colifor $\mathrm{m}$ at two treatment units (sedimentation tank and filtration units), for every three days, to assess the performance (removal efficiency) of the treatment units, was carried out. Similarly, the on site water quality was also assessed at the point of delivery $(\mathrm{POD})$ and point of use (PoU). Membrane filtration technique with loreal sulphate as media was used to carry out the microbial assessment. Upon getting unsatisfactory results of the treatment plant, the filter-bed media analysis was done at Multi Laboratory to examine the coefficient of uniformity of the media used for the filtration unit. The amount of chlorine needed was also assessed and the chlorination was done accordingly for three days to obser ve the impacts on the micro-or ganisms. The observation and questionnaire survey was carried out in the selected households in the service areas of the system to observe and analyze the behaviors of the local people in handling and managing the water resources at the household level. L astly, to document the operation and management system of the water supply system, few key informants related to the water supply system and user committee were interviewed. 


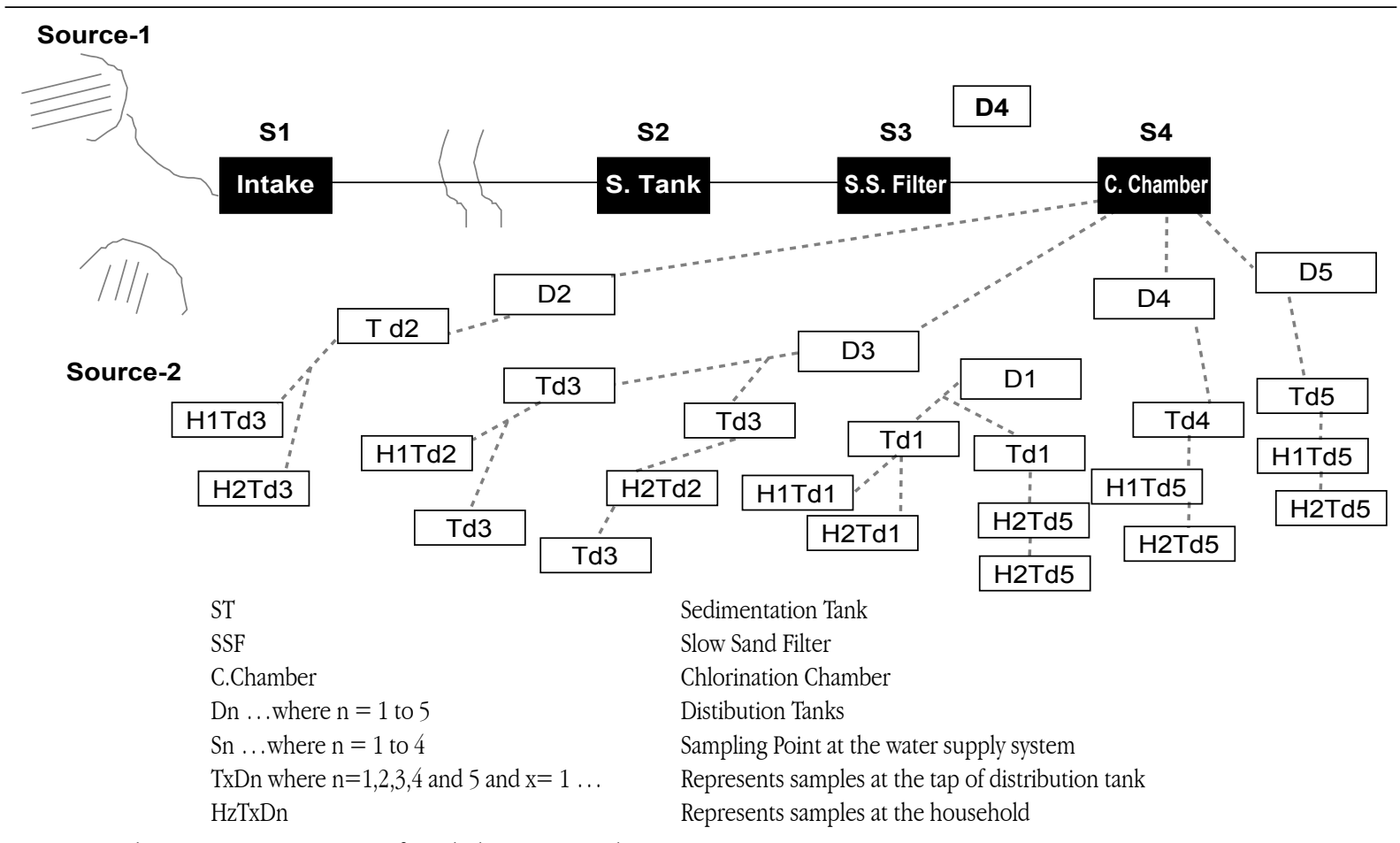

Figure 1 Schematic representation of Pasthali Water Supply system

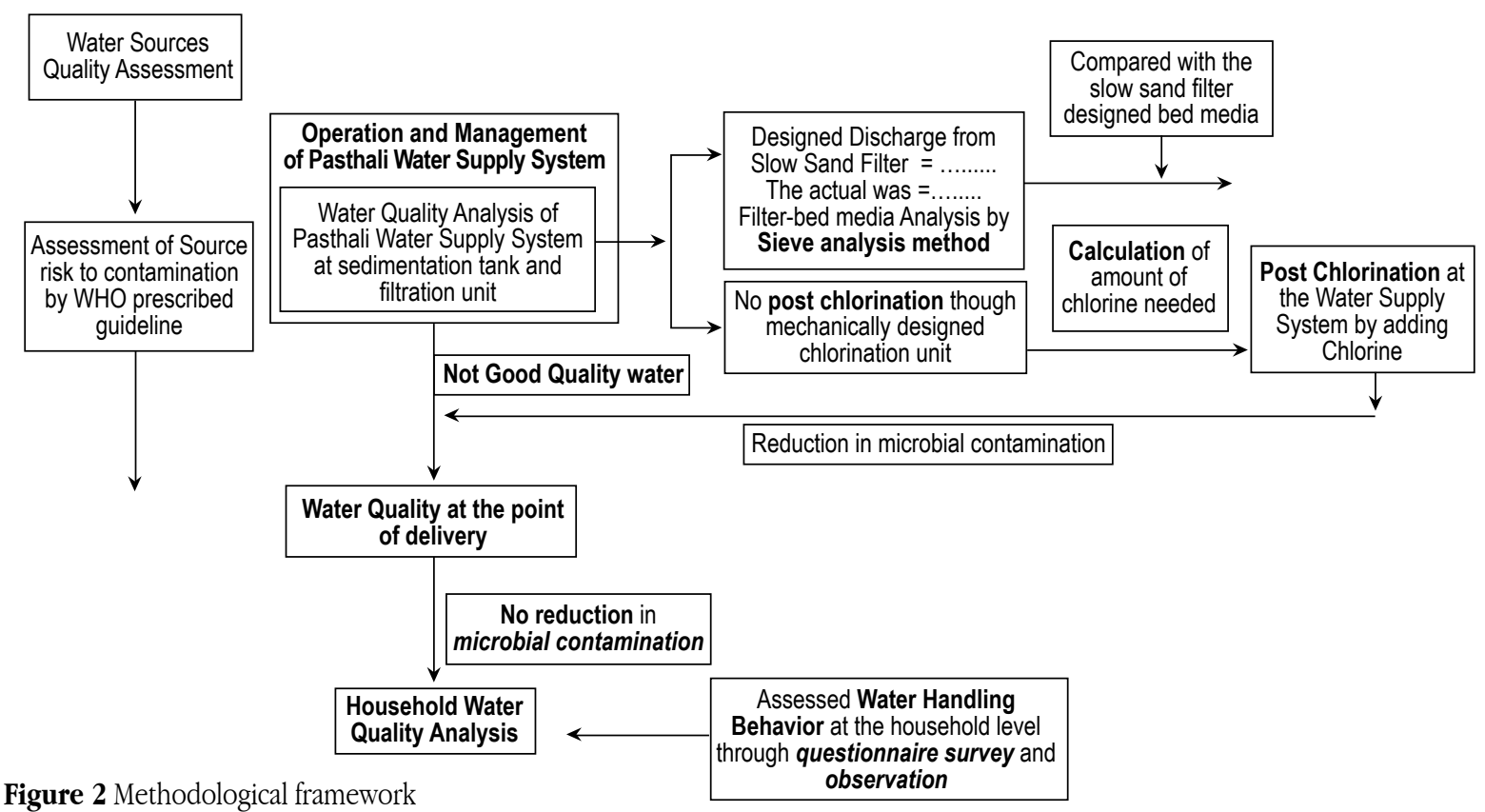

\section{Results and Discussion}

Water quality at the source of Pasthali water supply system The assessed physical, chemical and micro-biological parameters of the source water for Pasthali water supply system showed that water turbidity (13 NTU) is relatively higher than National Drinking Water Quality Standard (NDWQS, 2005). The higher turbidity could be because of rainy season when the present study was conducted. Similarly, the chemical parameters such as total hardness as $\mathrm{CaCO}_{3}$, chloride, fluoride, sulphate, total ammonia, manganese $(\mathrm{Mn})$ and lead $(\mathrm{Pb})$ are found within NDWQS with an exception of higher iron (Fe) content. The iron content in drinking water as per NDWQS is $0.3 \mathrm{mg} / \mathrm{l}$ and overall standard also it is 0.3 (3) $\mathrm{mg} /$. The reason is that the iron itself is not health hazard. Hwever, the higher concentration of iron leads to offensive odor and deposition of yellow strain in sanitar y appliances and clothes. 
But, the concentration of iron at source is $0.9 \mathrm{mg} / \mathrm{l}$. It is not recommended to install a separate treatment unit for iron removal in this particular case as it is not economical and slightly higher content of iron concentration does not have the health impact. Likewise, total coliform and faecal colifor $m$ are found to be too numerous to count (TNTC). From physicochemical point of view the water source was found relatively safe during the study period, but the source is not free from microbial contamination.

\section{Functionality of the treatment system based on the critical water quality parameters}

Treatment plant has been constructed to improve and provide good quality water to the people in 2012. The general layout of the system is shown in Figure 3.

The average turbidity removal efficiency of sedimentation tank is $67.58 \%$ (Fig. 4) compared to its theorectical value 70\% (Table 1). Similarly, the average turbidity removal efficiency of slow sand filter is $53.19 \%$ which is in contrast with the theoretical value $98-99 \%$ at all time. The very low efficiency indicates that water treatment units are not working properly. The reason is that there is no proper cleaning, heavy sludge deposition, and high quantity of algae growth. Further, the observed removal efficiency of the units was compared with the designed efficiency (Table 1).

Improper functioning of the treatment plant clearly implies that turbidity interferes the disinfection and provides the area where microorganisms do not come in contact with the disinfectant, though the turbidity does not affect health directly. Therefore, there is presence of disease causing or ganisms in rainy season. Faecal coliform test also justify that treatment plant is not working properly. Higher counts of faecal coliform were found in treated water, which could be due to high turbidity during the study period as higher turbidity implies higher concentrations of total dissolved solids which hinder the microbes from the action of chlorine.

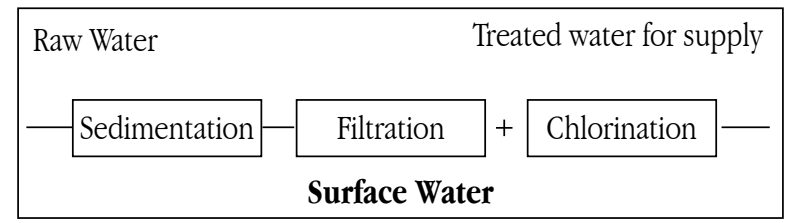

Figure 3 Treatment plant of the Pasthali water supply system

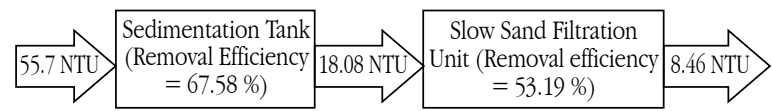

Figure 4 Turbidity removal efficiency of the treatment units
Table 1 Comparison of Turbidity Removal efficiency with the designed efficiency of the system

\begin{tabular}{lcccc}
\hline & \multicolumn{4}{c}{ Efficiency (\%) } \\
\hline Description & Standard* & \multicolumn{3}{c}{ Measured } \\
\cline { 2 - 5 } & & Minimum & Average & Maximum \\
\hline Sedimentation tank & 70 & 36 & 67.58 & 78.33 \\
Slow Sand Filter & $98-99$ & 35.71 & 53.19 & 64.29 \\
\hline *Theoretical removal efficiency of the designed units (Birdie \& Birdie, 1992)
\end{tabular}

\section{Causes of improper functioning of the system}

The system observation revealed that as per design, two filtration units of area $8 \mathrm{~m} \times 3 \mathrm{~m}$ each should be used to allow the design discharge to pass design flow as per standard rate of filtration 200 $1 / \mathrm{m}^{2} / \mathrm{hr}$. In the course of exploring the reasons for filtration unit not working properly, filter bed media was also analyzed (Fig. 5). Laboratory test of bed media shows unifor mity coefficient (U) of 2.03. For ensuring good quality water, the pore sizes are reasonably regular and there is sufficient porosity, this degree of unifor mity plays a significant role. Due to low uniformity coefficient of sand granules (2.03 instead of 3 to 5), it shows more even grading of sands, resulting the high filtration rate of about $400 \mathrm{l} / \mathrm{m}^{2} / \mathrm{hr}$ which is not acceptable. As a result, the efficiency of filter is low.

Lack of proper cleaning, heavy sludge deposition and high quantity of algae could be other reasons for improper function of the system. Though, there is provision of chlorination unit, it is not in operation. If the chlorination unit is in operation, required amount of chlorine dose can be put in water that can supply safe water to the tap stands. Therefore, the amount of chlorine required was calculated and chlorination was done for three days. Considering $0.2 \mathrm{mg} / \mathrm{l}$ of residual chlorine at the point of deliver y, $0.19 \mathrm{~kg}$ of chlorine was added to the volume of water demand $(279,446$ l/day) for three days.

In the field, water sample was analysed without and with chlorination at seven points of deliver $y$. Without chlorination water sample showed high content of faecal coliform. Increasing trend of faecal coliform was found in tap stands in compared to the outlet of slow sand filter. The reason for it can be improper maintenance of distribution tank and contamination in distribution pipeline.

\section{Water quality at the point of delivery}

The examined $\mathrm{pH}$ value for the water entering and leaving the treatment system is within the NDWQS value, 6.5-8.5. The minimum $\mathrm{pH}$ value at outlet of sedimentation tank is 7.79; at outlet of slow sand filter is 7.75 and at the selected seven tap stands is in between 7.78 and 7.52 . The $\mathrm{pH}$ value of water from sedimentation tank to tap stands is higher than the average value 7 . If the $\mathrm{pH}$ value is more in supplied water, it adversely affects its chlorine dose. The efficiency of chlorine is higher at lower $\mathrm{pH}$ value at which the percentage of $\mathrm{HOCl}$ is higher which is the main killing agent of mirco-organisms. At higher $\mathrm{pH}$, the $\mathrm{HOCl}$ converts into $\mathrm{OCl}$ ions and its strength is 100 times less than $\mathrm{HOCl}$ in disinfection process.

$\mathrm{HOCl}>\mathrm{OCl}->$ inorganic chloramines $>$ organic chloramines Strength decreases from left to right

\section{㓱TU-CDES}




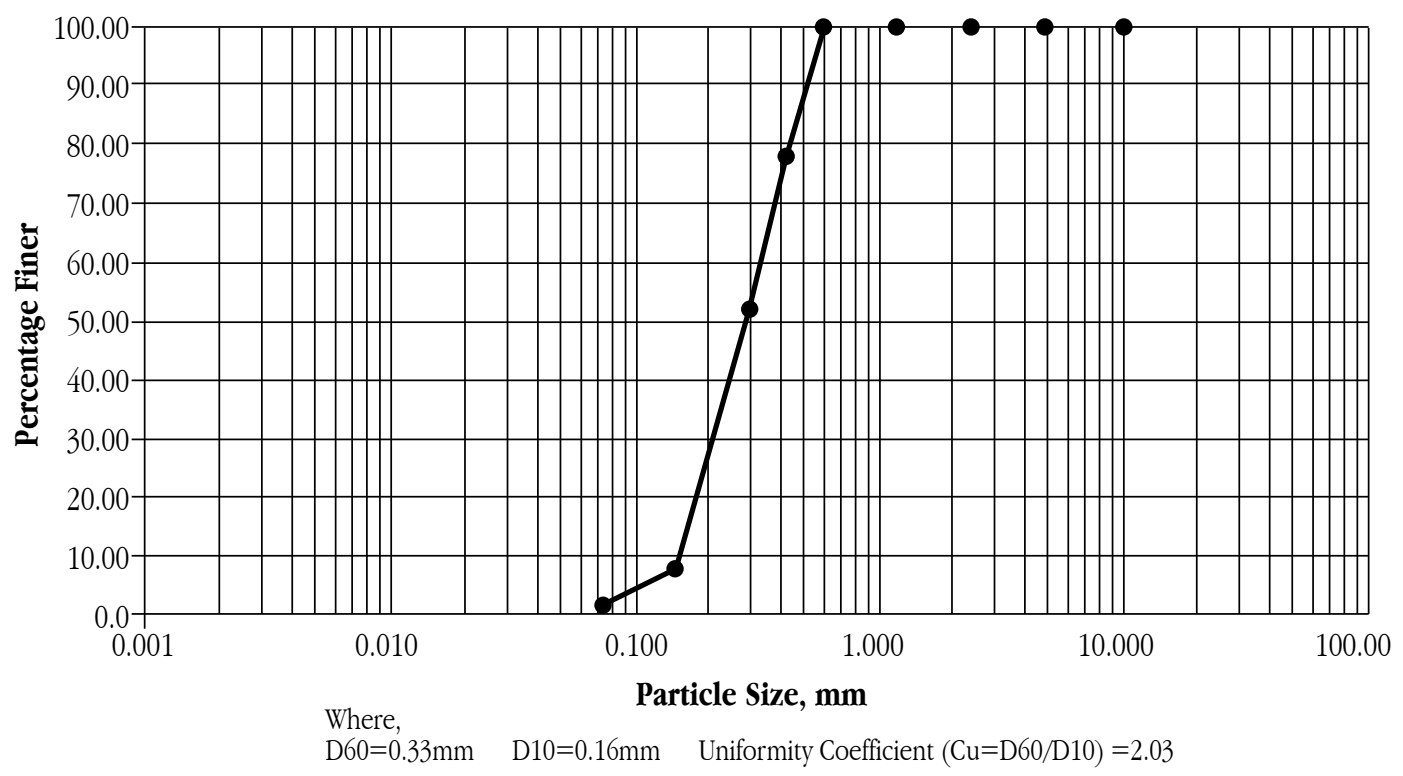

Figure 5 Filter bed-media sieve analysis

It could be concluded that the dose of chlorine should be more to find the same purity in disinfection at $\mathrm{pH}$ 7. Accordingly the chlorine should be applied, but this has not been practiced in the field. This less $\mathrm{HOCl}$ presence at higher $\mathrm{pH}$ could be one of the reasons for increment in microbial contamination at this point of deliver $y$ besides improper maintenance of the distribution tanks located at various places. Regarding chlorination, manually feeding of calculated amount of chlorine was added and water analysis was car ried out for additional three days. The chlorination process shows drastic changes in faecal coliform count in the tap stands. The reason is that presence of free residual chlorine $0.2 \mathrm{mg} / \mathrm{l}$ helps to kill microorganisms by collapsing its cells.

\section{Water quality at household level}

The faecal coliform contamination at the household level shows increment than what was obser ved at the point of deliver $y$. Chlorination resulted in significant decrease in the microbial concentration at the point of delivery. However, the water analysis at the point of use has shown increment in microbial contamination. The reasons being so was improper handling of water, storage, and unhygienic environment of surrounding household based on the observation. Unhygienic toilet practice is also another cause. Regarding the toilet use in the study area, the record of Panauti Municipality shows that out of 509 households of the water supply project area, almost 88\% household has toilet. Only 10-12\% households lack toilets.

\section{Risk assessment of Pasthali water supply system}

On the basis of World Health Organization (WHO) Guideline for drinking water quality volume 3's sanitary inspection for surface source was done (Fig. 6). The results of sanitary survey for surface source water of Pasthali water supply system shows contamination risk score 4/10 and faecal coliform number 11-100 C. The combine analysis of sanitary hazard and faecal coliform grading shows that the project is in inter mediate to high risk categor $y$ and it needs higher priority for water source conservation to provide safe water (Fig. 6).

Operation and management of Pasthali water supply project Water user committee (WUC)

The project is being managed by a water user committee (WUC). The Pasthali WUC was formed in 2003 for operation of the scheme. According to Water Resource Act-1992, the WUC was registered in 2004 at the district water resource committee of Kavre. The WUC formed initially played important role for solving problems related to the dispute of source and transmission line. Initially, people of Bete Khola did not want to provide the source to the people of Pasthali. After holding several rounds of discussion, people of the Beta kbola told the people of Pasthali area "Kakakul" that means the areas of water scarce, where people do not get water so the people of Bete Khola (river) were ready to provide the source of Bete Kbola in humanitarian ground. Similarly, there was debate during layout of transmission line. In request of the WUC, the debate was also solved.

\section{Sanitary inspection risk score}

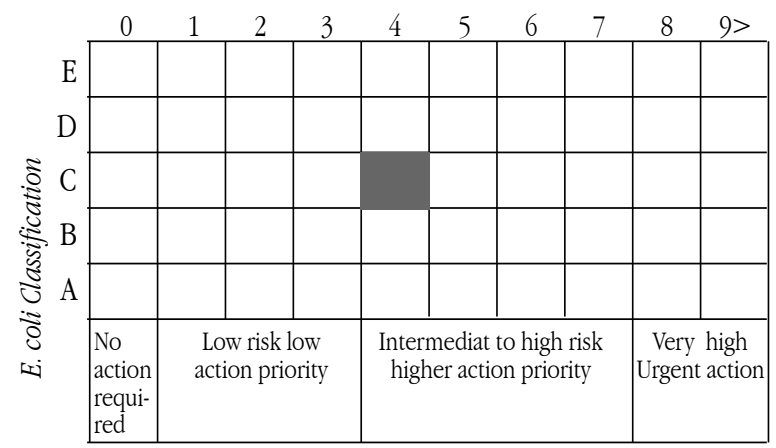

Figure $\mathbf{6}$ Sanitary inspection risk score 
The current WUC comprised 71\% male and 29\% female. Turn by turn, each members of the user committee monitor the source/intake area as per need. The tenure of WUC is three years and committee members are selected from the community on the basis of the member's activeness. In the statutes of the user committee, there is provision of election for selecting the executive committee. The WUC hosts weekly meeting to discuss issues and minute of those meetings are maintained. The WUC has bank account for the transaction of the money and is operated by the authorized signature of three executive members of user committee namely chair person, secretary and treasurer.

Pasthali water supply user committee has no practice of coordination with other related organization to improve the quality of drinking water, health and sanitation. But, it coordinated with Panauti municipality for construction of the Pasthali water supply user committee office building.

Office structure for management of water supply system There are eight staffs working under the committee. The staff includes manager, plumbers, meter reader, office assistant and care taker for the treatment plants. The WUC has its own office building. Among the eight staffs, five are technical staffs. The plumbers have taken training on repair and maintenance. When there is need of technical suggestion for the water supply project, there is a trend to tak e advice from the technical know-how knowledgeable person of the user committee and its technical staffs. Water users also take-care of the interruption in the water supply scheme. As a result, user committee and its office are cautious in term of regular water supply. Similarly, the staff from Water Supply and Sanitation Division office, Dhulikhel visits the water supply project area, though there is no standard monitoring of the scheme by the supervising agency.

Nowadays, there are problems especially leakage in pipeline and sometimes pipes are broken. There is no practice of water quality examination and no testing kits with WUC and the water is supplied in the households without any quality measurement. In the project area, though the water bor ne disease incidences have been reduced to some extents, the diarrhea, and dysentery like diseases are still occurring sporadically as informed by the people of the project area.

Table 2 Monthly income and expenses (Aug./Sept. 2014)

\section{Operation and maintenance}

\section{(a) Financial resource management}

The financial resource was estimated, based on the infor mation provided by the water user association. The total monthly income and expenses of the water supply system are NRs. 24,300 and NRs. 25,518 respectively. The income and expenditure figure indicates that per month expenditure is more than the income (Table 2). Till the study period, the user association char ge NRs. 2800 for installing a tap. This cost has been using to cover all the expenses. The activity of tap installation has completed in Pasthali area and existing water tariff seems not sufficient to cover the operating and management cost.

\section{(b) Non-revenue water}

In connection to financial loss, it was also discussed with the WUC about how the income can be increased or the financial loss for the system can be managed. The discussion brought a possibility of surplus treated water termed as non-revenue water (NRW) in the system. If the surplus treated water is sold to the nearby villages, after proper treatment deemed necessar y, can help generate extra income. The generated additional income ultimately strengthens financial aspects of the system and supports for its management. The NRW and the extra revenues possibly could be generated (Table 3). The unit cost of water that is being charged is NRs. $9 / \mathrm{m}^{3} /$ day, the calculation on conservative side yields NRs 4,860, which can contribute to the financial basket of Pasthali water supply system (Table 3).

Table 3 Surplus discharge per month (Aug./Sept. 2014)

\begin{tabular}{cccc}
\hline $\begin{array}{l}\text { Surplus discharge } \\
\text { (Non-revenue water) } \\
(\mathrm{m} 3 / \text { day })\end{array}$ & $\begin{array}{c}\text { Rate per unit } \\
\text { (NRs.) }\end{array}$ & Amount/day & $\begin{array}{c}\text { Amount/month } \\
\text { (NRs) }\end{array}$ \\
\hline 18 & 9.00 & 162.00 & $4,860.00$ \\
\hline
\end{tabular}

\section{(c) Water quality management cost}

As discussed earlier, chlorination was not in practice during the study period, though the chlorination unit is present in the system. If the chlorination unit is in operation, the required amount of chlorine dose can be added in water to yield safe water to the tap stands. Addition of chlorine needs additional cost which was also calculated in the study. The quantity of chlorine required and its associated cost was calculated to be NRS. 866/month. The inclusion of both NRW cost and the cost incurred in chlorination results in NRs 2,776.00 as a surplus amount per month, which gives little relief to sustain the system.

\begin{tabular}{lccclc}
\hline & \multicolumn{2}{c}{ Income Per Month } & \multicolumn{2}{c}{ Expenses Per Month } \\
\hline Description & Number & Min. Tariff (NRs.) & Amount (NRs.) & Description & Amount (NRs.) \\
\hline Public tap & 45 & 200.00 & 9000.00 & Salary of staff & 22258.00 \\
Private tap & 170 & 90.00 & 15300.00 & Office expense & 1000.00 \\
& & & Electricity & 260.00 \\
& & & & Operation \& management expenses & 2000.00 \\
& & & $\mathbf{2 4 , 3 0 0}$ & & $\mathbf{2 5 . 5 1 8 . 0 0}$
\end{tabular}




\section{Conclusion}

The water source of Pasthali water supply system needs immediate protection by fencing to control the access to the people and animals and failure of such control can lead to high contamination at the source, which demands increased cost for its treatment in the future. The study concludes that the failure of exact implementation and operation of the unit along with chances of re-contamination of supplied water as result of no residual chlorine and unsanitaray condition around the distribution tanks. Lack of proper awareness on water handling and management is seen as a major cause of enhanced microbial contamination at the households. Pasthali water user committee is local supplier, legally responsible for good quality water supply to the consumer. But, such type of responsibility is not mentioned in the statutes of Pasthali water supply project. Insufficiency of the collected water tariff to sustain the system in future could be solved by generating finance by selling NRW to the nearby villages at relatively high price per unit of water after proper treatment. In order to ensure the proper functioning of the system and potable water, the filter bed media should be replaced with proper sand grading (with uniformity coefficient less than 2), as prescribed in the design, to maintain the uniform discharge at its outlet. The study seeks the need of awareness in the community for household level water handling and management along with the point of use treatment.

\section{References}

Birdie, G.S., \& Birdie, J.S. (1992). Water Supply and Sanitary Engineering. India: Dhapat Rai and Sons.

DWSS. (2012). Nepal Water Safety Plan Key Materials WSP 10 steps and formats. Guideline. Kathmandu, Nepal: Government of Nepal Department of Water Supply and Sewerage.

GoN, \& UN. (2013).Nepal Millennium Development Goals. Nepal Millennium Development Goals- Progress Report 2013.

Kathmandu, Nepal: National Planning Commission and United Nations.

HMG/N, 2005. National Water Plan. National Plan. Kathmandu, Nepal: His Majesty's Government/Nepal.

Nepal, G.D., (2016). Community resilient water safety plan (CRWSP) for water supply system sustainability and public health based target. Journal of Geo and Environmental Science Research, 4(1), pp.01-09.

NMIP/DWSS. (2011). Nationwide Coveraege and Functionality Status of Water Supply and Sanitation in Nepal. Status report. Kathmandu, Nepal: Department of Water Supply and Sewerages National Management Information Project and Department of Water Suppliy and Sewerage.

WHO. (1999). Guidelines for Drinking Water Quality. Guidelines. Delhi: B.S Publishers and Distributors World Health Organization. 